STUDI

FRANCESI

\section{Studi Francesi}

Rivista quadrimestrale fondata da Franco Simone

185 (LXII | II) | 2018

OCTAVE MIRBEAU: UNE CONSCIENCE AU TOURNANT

DU SIEECLE - sous la direction de Ida Merello

\title{
SILVÈRE MENEGALDO, Le dernier ménestrel? Jean de Le Mote, une poétique en transition (autour de 1340)
}

\section{Maria Colombo Timelli}

\section{(2) OpenEdition \\ Journals}

\section{Édition électronique}

URL : http://journals.openedition.org/studifrancesi/13197

DOI : $10.4000 /$ studifrancesi. 13197

ISSN : 2421-5856

Éditeur

Rosenberg \& Sellier

\section{Édition imprimée}

Date de publication : 1 août 2018

Pagination : 300-301

ISSN : 0039-2944

\section{Référence électronique}

Maria Colombo Timelli, « silvère menegaldo, Le dernier ménestrel? Jean de Le Mote, une poétique en transition (autour de 1340) », Studi Francesi [En ligne], 185 (LXII | II) | 2018, mis en ligne le 01 septembre 2018, consulté le 08 janvier 2021. URL : http://journals.openedition.org/studifrancesi/13197 ; DOI : https://doi.org/10.4000/studifrancesi.13197

Ce document a été généré automatiquement le 8 janvier 2021.

\section{(c)}

Studi Francesi è distribuita con Licenza Creative Commons Attribuzione - Non commerciale - Non opere derivate 4.0 Internazionale. 


\title{
SILVÈRE MENEGALDO, Le dernier ménestrel? Jean de Le Mote, une poétique en transition (autour de 1340)
}

\author{
Maria Colombo Timelli
}

\section{RÉFÉRENCE}

SILVÈRE MENEGALDO, Le dernier ménestrel? Jean de Le Mote, une poétique en transition (autour de 1340), Genève, Droz, 2015, «Publications Romanes et Françaises» CCLXV, 428 pp.

1 Poète et musicien de la première moitié du XIV siècle, peu fréquenté par la critique actuelle et mal servi par les éditions disponibles de ses œuvres, Jean de Le Mote trouve chez Silvère Menegaldo son premier biographe: ce volume important, issu d'une HDR soutenue en 2014, s'impose par ailleurs aussi pour le cadre qu'il offre de la culture, non seulement littéraire, de ces décennies.

2 Un premier chapitre (Jean de Le Mote, ménestrel, pp. 23-90) fait le point, d'abord, sur la vie de Jean de Le Mote, tout en soulignant le caractère limité et souvent incertain des témoignages qui nous sont parvenus: originaire du Hainaut, sa carrière se déploya entre sa région natale (1325-1326), l'Angleterre (1339), la France (1340), l'Angleterre encore (vers 1341-1343) dans les années qui virent les débuts de la guerre de Cent Ans. Son œuvre ne nous est conservée que partiellement: elle compte les Regrets Guillaume, le Parfait du paon, la Voie d'Enfer et Paradis, transmis dans six manuscrits au total, mais une partie au moins de sa production poétique est sans doute perdue. Un paragraphe intéressant porte sur le «statut» de Jean de Le Mote: qualifié de menistrallus à la cour d'Angleterre, il était indubitablement autant musicien que poète.

Les chapitres qui suivent analysent les œuvres de Le Mote en suivant l'ordre chronologique de leur composition. Les Regrets Guillaume, comte de Hainaut (chapitre II, pp.91-143), plainte funèbre allégorique de quelque 4600 octosyllabes à insertions lyriques (trente ballades), sont étudiés ici dans les détails; sans tomber dans une 
réévaluation aveugle, en affirmant au contraire que les Regrets ne constituent pas à ses yeux «une grande réussite» (p. 141), S.M. en souligne quelques mérites: une certaine virtuosité poétique, ainsi qu'une recherche de la variatio à l'intérieur d'une œuvre dont le caractère régulier et répétitif est certainement voulu.

Composé en 1348 pour Simon de Lille, orfèvre du roi Philippe VI, le Parfait du Paon (4000 alexandrins environ, en laisses monorimes) s'inscrit dans le «cycle» homonyme en se rattachant par sa matière au Roman d'Alexandre d'une part, à Perceforest de l'autre. La continuité recherchée avec les Vœux et le Restor n'exclut cependant pas les différences, et S.M. met justement en relief comment Le Mote, tout en s'inspirant de près de Jacques de Longuyon, parvient à en renverser l'idéologie et à achever le cycle (chapitre III, pp. 145-201).

Rédigée la même année pour le même commanditaire, la Voie d'Enfer et de Paradis (plus de 4600 octosyllabes) appartient en revanche au genre des «voies de l'au-delà». Dans le chapitre qu'il lui consacre (IV, pp. 203-259), S.M. s'interroge sur le rapport que ce voyage allégorique entretient avec ce «genre» d'un côté et avec la forme d'Hélinand de Froidmont - dont il adopte la strophe - de l'autre. Proche de l'œuvre de Pierre de l'Hôpital, la Voie de Le Mote exploite aussi d'autres sources (sermons en vers, Reclus de Molliens, autres «voies») et constitue «le poème le plus réussi» du «ménestrel» (p. 259).

Le riche corpus des Ballades (42 au total, dont trente dans les Regrets, huit dans le Parfait, quatre «mythologiques» transmises dans le ms. lat. 3343 de la BnF) fait l'objet du cinquième et dernier chapitre (pp. 261-317): il est donc traité ici comme un ensemble lyrique dans quelque mesure autonome, à situer dans le contexte littéraire du temps. De par sa production abondante, Jean de Le Mote semble avoir contribué à «populariser» (p. 317) une forme qui connaittra son épanouissement avec Guillaume de Machaut autour de 1350.

7 La Conclusion générale (pp. 319-329) offre un bilan équilibré de l'œuvre du Poète, riche et diversifiée bien que très resserrée dans le temps. Le caractère «épigonal» (p. 321) du Parfait et de la Voie s'oppose par ailleurs à l'originalité formelle des Ballades, dont l'influence se manifesta sans doute sur Chaucer en Angleterre, plus probablement chez les poètes français de la seconde moitié du siècle, Machaut et Froissart en particulier. Les Annexes ajoutent une documentation complémentaire très utile: Exempla enchâssés dans les Regrets (résumés et sources: pp. 331-345); tableaux métriques des Ballades (pp. 346-352); textes commentés des Ballades «mythologiques» de Jean de Le Mote, Philippe de Vitry, Jean Campion (pp. 353-385). Une Bibliographie sélective (pp. 387-421) est encore suivie de l'Index des auteurs et des œuvres (pp. 423-426). 